\title{
A justiça social na globalização: Redistribuição, reconhecimento e participação
}

Social Justice in Globalization: Redistribution, Recognition, and Participation

La justice sociale dans la globalisation: Redistribution, reconnaissance et

participation

\section{Nancy Fraser}

Tradutor: Teresa Tavares

\section{OpenEdition}

\section{Journals}

\section{Edição electrónica}

URL: http://journals.openedition.org/rccs/1250

DOI: $10.4000 /$ rccs. 1250

ISSN: 2182-7435

\section{Editora}

Centro de Estudos Sociais da Universidade de Coimbra

\section{Edição impressa}

Data de publição: 1 Outubro 2002

Paginação: 07-20

ISSN: 0254-1106

\section{Refêrencia eletrónica}

Nancy Fraser, «A justiça social na globalização: Redistribuição, reconhecimento e participação », Revista Crítica de Ciências Sociais [Online], 63 | 2002, colocado online no dia 01 outubro 2012, criado a 19 abril 2019. URL : http://journals.openedition.org/rccs/1250; DOI : 10.4000/rccs.1250 


\section{NANCY FRASER}

New School of Social Research, Nova lorque

\section{A justiça social na globalização: Redistribuição, reconhecimento e participação}

Centrando-se na actual politização da cultura e particularmente nas lutas pelo reconhecimento, a autora identifica três problemas que ameaçam a justiça social no contexto da globalização: a reificação das identidades colectivas, a substituição da redistribuição pelo reconhecimento e a forma como diferentes tipos de luta estão a enquadrar desajustadamente os processos transnacionais. O texto discute três estratégias conceptuais para neutralizar os riscos derivados destes problemas, todas elas baseadas em traços emergentes da globalização. Para contrariar o risco da reificação, propõe uma concepção do reconhecimento baseada no estatuto que não conduz a uma política de identidade. Para contrariar o risco da substituição, a autora propõe uma concepção bidimensional de justiça que abrange tanto o reconhecimento como a distribuição. Para contrariar a ameaça do enquadramento desajustado, propõe uma concepção de soberania de múltiplos níveis que descentra o enquadramento nacional.

\section{Introdução}

Ao escolher a frase "Globalização: fatalidade ou utopia?" como título deste colóquio, os organizadores sugerem duas coisas: em primeiro lugar, que estamos hoje à beira de uma importante transição social e, em segundo lugar, que as circunstâncias exigem que tomemos uma posição relativamente a essa transição. Concordo com ambas as sugestões. Mesmo que não possamos ainda caracterizar da melhor forma a globalidade da mudança, é evidente que estão a dar-se transformações profundas. Uma transição importante, da perspectiva do "Primeiro Mundo", é a que se refere à passagem de uma fase fordista do capitalismo, centrada na produção em massa, em sindicatos fortes e na normatividade do salário familiar, para uma fase pós-fordista, caracterizada pela produção virada para nichos do mercado, pelo declínio da sindicalização e pelo aumento da participação das mulheres no mercado de trabalho. Outra mudança relacionada com esta tem a ver com a transição de uma sociedade industrial, baseada nas tecnologias de manufactura da segunda revolução industrial, para o que tem 
sido apelidado por alguns de "sociedade do conhecimento", baseada nas tecnologias de informação da terceira revolução industrial. Há ainda que referir a mudança de uma ordem internacional dominada por Estados-nação soberanos para uma ordem globalizada em que os enormes fluxos transnacionais do capital restringem as capacidades de governação dos Estados nacionais.

Tomo todos estes processos como parte do que se entende por globalização e penso que todos estão relacionados com um outro traço fundamental da presente constelação: a crescente proeminência da cultura na ordem emergente. Esta nova proeminência da cultura pode ser vista numa série de aspectos: na maior visibilidade dos "trabalhadores simbólicos", por contraste com os trabalhadores manuais, na economia global da informação; no declínio da centralidade do trabalho relativamente à religião e à etnicidade na constituição das identidades colectivas; na maior consciência do pluralismo cultural na esteira do aumento da imigração; na intensificação da hibridação cultural, fomentada não só por contactos pessoais transculturais, mas também pela comunicação electrónica; na proliferação e rápida difusão de imagens pelas indústrias globais da publicidade e do entretenimento de massas; e por último, como consequência de todas estas mudanças, numa nova consciência reflexiva dos "outros" e, por isso, uma nova ênfase na identidade e na diferença.

Contudo, aquilo que mais me interessa é o efeito desta nova proeminência da cultura sobre a política - e, portanto, sobre as perspectivas de justiça social. Assim, gostaria de sugerir que um outro traço que define a globalização é a politização generalizada da cultura, especialmente nas lutas pela identidade e diferença - ou, como passarei a designá-las, as lutas pelo reconhecimento - que explodiram nos últimos anos. De facto, hoje em dia, a reivindicação de reconhecimento é a força impulsionadora de muitos conflitos sociais, desde batalhas sobre o multiculturalismo a lutas sobre as relações sociais de sexo e a sexualidade, desde campanhas pela soberania nacional e autonomia subnacional a esforços para construir organizações políticas transnacionais, desde a jibad fundamentalista aos revivescentes movimentos internacionais de direitos humanos. É certo que estas lutas são heterogéneas, situando-se numa escala que vai daquelas que são claramente emancipatórias às que são absolutamente condenáveis. Não obstante, o seu recurso a uma gramática comum é notório, apontando para uma profunda mudança dos ventos políticos: um ressurgimento maciço da política de estatuto.

O reverso deste ressurgimento é um declínio correspondente da política de classe. Outrora a gramática hegemónica da contestação política, as reivin- 
dicações de igualdade económica são hoje menos salientes do que durante o apogeu fordista do Estado-Providência keynesiano. Os partidos políticos que antes se identificavam com projectos de redistribuição igualitária abraçam hoje uma escorregadia "terceira via", cuja substância verdadeiramente emancipatória, quando a têm, está mais relacionada com o reconhecimento do que com a redistribuição. Entretanto, os movimentos sociais que não há muito tempo exigiam com audácia uma partilha equitativa dos recursos e da riqueza já não são exemplificativos do espírito da época. É certo que não desapareceram totalmente, mas o seu impacto tem sido grandemente reduzido. Para além do mais, mesmo nos melhores casos, quando as lutas pela redistribuição não se apresentam como antitéticas às lutas pelo reconhecimento, elas tendem a ser dissociadas destas últimas.

Portanto, em geral, a globalização está a gerar uma nova gramática de reivindicação política. Nesta constelação, o centro de gravidade foi transferido da redistribuição para o reconhecimento. Como deveremos caracterizar esta transição? Quais são as suas implicações para a justiça social?

A meu ver, as perspectivas são ambivalentes. Por um lado, a viragem para o reconhecimento representa um alargamento da contestação política e um novo entendimento da justiça social. Já não restrita ao eixo da classe, a contestação abarca agora outros eixos de subordinação, incluindo a diferença sexual, a "raça", a etnicidade, a sexualidade, a religião e a nacionalidade. Isto constitui um claro avanço relativamente aos restritivos paradigmas fordistas que marginalizavam tal contestação. Para além disso, a justiça social já não se cinge só a questões de distribuição, abrangendo agora também questões de representação, identidade e diferença. Também neste aspecto constitui um avanço positivo relativamente aos redutores paradigmas economicistas que tinham dificuldade em conceptualizar males cuja origem reside, não na economia política, mas nas hierarquias institucionalizadas de valor.

Por outro lado, não é absolutamente nada evidente que as actuais lutas pelo reconhecimento estejam a contribuir para complementar e aprofundar as lutas pela redistribuição igualitária. Antes pelo contrário: no contexto de um neoliberalismo em ascensão, podem estar a contribuir para deslocar as últimas. Se assim for, os recentes ganhos no nosso entendimento da justiça podem estar entrelaçados com uma perda trágica. Em vez de chegarmos a um paradigma mais amplo e rico, capaz de abarcar tanto a redistribuição como o reconhecimento, estaremos a trocar um paradigma truncado por outro: um economicismo truncado por um culturalismo igualmente truncado. O resultado seria um exemplo clássico de desenvolvimento combina- 
do e desigual: as recentes conquistas notáveis no eixo do reconhecimento corresponderiam a um progresso paralisado, se não mesmo a francas perdas, no eixo da distribuição.

Esta é, de qualquer das formas, a minha leitura das tendências actuais. A seguir delinearei uma abordagem que responde a este diagnóstico e que visa evitar a sua realização plena. O que tenho a dizer divide-se em três partes, cada uma das quais corresponde a um risco inerente à actual trajectória da globalização. Considerarei em primeiro lugar o risco da substituição das lutas pela redistribuição pelas lutas pelo reconhecimento, em vez de estas complementarem ou enriquecerem aquelas. Para neutralizar este risco, proporei uma análise da justiça social que é suficientemente ampla para incluir o leque total de preocupações suscitadas pela globalização, mesmo as desigualdades de classe e as hierarquias de estatuto. Em segundo lugar, considerarei o risco da actual centralidade da política cultural, que está a reificar as identidades sociais e a fomentar um comunitarismo repressivo. Para que este risco seja neutralizado, proponho uma concepção não-identitária do reconhecimento adequada à globalização, uma concepção que promova a interacção entre as diferenças e que estabeleça sinergias com a redistribuição. Em terceiro e último lugar, examinarei o risco de a globalização estar a subverter as capacidades do Estado para reparar ambos os tipos de injustiça. A fim de neutralizar este risco, proporei uma concepção múltipla de soberania que descentre o enquadramento nacional. Em cada um dos casos, as concepções propostas assentam em potencialidades emancipatórias que estão a despontar na actual constelação.

Portanto, em termos gerais, não tratarei a globalização como fatalidade ou utopia, mas antes como um processo de dupla face, que carrega em si tanto riscos como possibilidades. Desta forma, procurarei esclarecer os riscos e identificar os recursos com que lhes poderemos fazer frente.

\section{Contrariar a substituição: uma concepção bidimensional da justiça social}

Uma das ameaças à justiça social na globalização é resultado de uma ironia histórica: a transição da redistribuição para o reconhecimento está a ocorrer apesar (ou por causa) da aceleração da globalização económica. Desta forma, os conflitos identitários alcançaram estatuto paradigmático exactamente no momento em que o agressivo capitalismo globalizante conduzido pelos Estados Unidos está a exacerbar radicalmente as desigualdades económicas. Como resultado, a viragem para o reconhecimento encaixou-se perfeitamente num neoliberalismo económico que deseja acima de tudo reprimir a memória do igualitarismo socialista. Neste con- 
texto, as lutas pelo reconhecimento estão a contribuir menos para suplementar, tornar mais complexas e enriquecer as lutas pela redistribuição do que para as marginalizar, eclipsar e substituir. Chamo a isto o problema da substituição.

Esta substituição ameaça a nossa capacidade de conceptualizar a justiça social num mundo em processo de globalização. Para evitarmos truncar a nossa visão da emancipação e, assim, entrar involuntariamente em conluio com o neoliberalismo, necessitamos de revisitar o conceito de justiça. O que é preciso é uma concepção ampla e abrangente, capaz de abranger pelo menos dois conjuntos de preocupações. Por um lado, ela deve abarcar as preocupações tradicionais das teorias de justiça distributiva, especialmente a pobreza, a exploração, a desigualdade e os diferenciais de classe. Ao mesmo tempo, deve igualmente abarcar as preocupações recentemente salientadas pelas filosofias do reconhecimento, especialmente o desrespeito, o imperialismo cultural e a hierarquia de estatuto. Rejeitando formulações sectárias que caracterizam a distribuição e o reconhecimento como visões mutuamente incompatíveis da justiça, tal concepção tem de abrangê-las a ambas. O resultado seria uma concepção bidimensional de justiça, o único tipo de concepção capaz de abranger toda a magnitude da injustiça no contexto da globalização.

Passo a explicar. A abordagem que proponho requer que se olhe para a justiça de modo bifocal, usando duas lentes diferentes simultaneamente. Vista por uma das lentes, a justiça é uma questão de distribuição justa; vista pela outra, é uma questão de reconhecimento recíproco. Cada uma das lentes foca um aspecto importante da justiça social, mas nenhuma por si só basta. A compreensão plena só se torna possível quando se sobrepõem as duas lentes. Quando tal acontece, a justiça surge como um conceito que liga duas dimensões do ordenamento social - a dimensão da distribuição e a dimensão do reconbecimento.

Do ponto de vista distributivo, a injustiça surge na forma de desigualdades semelhantes às da classe, baseadas na estrutura económica da sociedade. Aqui, a quintessência da injustiça é a má distribuição, em sentido lato, englobando não só a desigualdade de rendimentos, mas também a exploração, a privação e a marginalização ou exclusão dos mercados de trabalho. Consequentemente, o remédio está na redistribuição, também entendida em sentido lato, abrangendo não só a transferência de rendimentos, mas também a reorganização da divisão do trabalho, a transformação da estrutura da posse da propriedade e a democratização dos processos através dos quais se tomam decisões relativas ao investimento. 
Do ponto de vista do reconhecimento, por contraste, a injustiça surge na forma de subordinação de estatuto, assente nas hierarquias institucionalizadas de valor cultural. A injustiça paradigmática neste caso é o falso reconhecimento, que também deve ser tomado em sentido lato, abarcando a dominação cultural, o não-reconhecimento e o desrespeito. O remédio é, portanto, o reconhecimento, igualmente em sentido lato, de forma a abarcar não só as reformas que visam revalorizar as identidades desrespeitadas e os produtos culturais de grupos discriminados, mas também os esforços de reconhecimento e valorização da diversidade, por um lado, e, por outro, os esforços de transformação da ordem simbólica e de desconstrução dos termos que estão subjacentes às diferenciações de estatuto existentes, de forma a mudar a identidade social de todos.

Do ponto de vista distributivo, portanto, a justiça requer uma política de redistribuição. Do ponto de vista do reconhecimento, em contraponto, a justiça requer uma política de reconhecimento. A ameaça de substituição surge quando as duas perspectivas da justiça são consideradas mutuamente incompatíveis. Nesse caso, as reivindicações de reconhecimento desligam-se das reivindicações de redistribuição, acabando por as eclipsar.

Quando, contudo se sobrepõem as duas perspectivas, o risco de substituição pode ser neutralizado. A justiça surge então como uma categoria bidimensional que abrange ambos os tipos de reivindicação. Desta perspectiva bifocal, torna-se desnecessário optar entre uma política de reconhecimento e uma política de redistribuição, impondo-se, pelo contrário, uma política que abarque os dois aspectos.

A aceleração da globalização faz com que, em princípio, tal política se torne possível. Nesta sociedade, como vimos, a identidade já não está exclusivamente ligada ao trabalho e as questões da cultura são intensamente politizadas. Contudo, a desigualdade económica continua a manifestar-se desmedidamente, uma vez que a nova economia global da informação está a alimentar importantes processos de recomposição de classe. Além disso, a actual população diversificada de trabalhadores simbólicos, trabalhadores de serviços, trabalhadores manuais, trabalhadores temporários e a tempo parcial, bem como os socialmente excluídos, tem extrema consciência das múltiplas hierarquias de estatuto, incluindo as ligadas à diferença sexual, "raça", etnicidade, sexualidade e religião. Neste contexto, não é viável nem um economicismo redutor, nem um culturalismo banal. Pelo contrário, a única perpectiva adequada é uma perspectiva bifocal que abarque tanto o reconhecimento como a distribuição.

Todavia, não é fácil combinar a redistribuição e o reconhecimento, uma vez que isto exige que se submetam as duas dimensões de justiça a uma 
medida normativa comum. O que é preciso é um único princípio normativo que inclua as reivindicações justificadas quer de redistribuição, quer de reconhecimento, sem reduzir umas às outras. Com este propósito, proponho o princípio de paridade de participação, segundo o qual a justiça requer arranjos sociais que permitam a todos os membros (adultos) da sociedade interagir entre si como pares. São necessárias pelo menos duas condições para que a paridade participativa seja possível. Primeiro, deve haver uma distribuição de recursos materiais que garanta a independência e "voz" dos participantes. Esta condição impede a existência de formas e níveis de dependência e desigualdade económicas que constituem obstáculos à paridade de participação. Estão excluídos, portanto, arranjos sociais que institucionalizam a privação, a exploração e as flagrantes disparidades de riqueza, rendimento e tempo de lazer que negam a alguns os meios e as oportunidades de interagir com outros como pares. Em contraponto, a segunda condição para a paridade participativa requer que os padrões institucionalizados de valor cultural exprimam igual respeito por todos os participantes e garantam iguais oportunidades para alcançar a consideração social. Esta condição exclui padrões institucionalizados de valor que sistematicamente depreciam algumas categorias de pessoas e as características a elas associadas. Portanto, excluem-se padrões institucionalizados de valor que negam a alguns o estatuto de parceiros plenos nas interacções - quer ao imputar-lhes a carga de uma "diferença" excessiva, quer ao não reconhecer a sua particularidade.

Ambas as condições são necessárias à paridade participativa, nenhuma sendo por si só suficiente. A primeira traz à tona preocupações tradicionalmente associadas à teoria da justiça distributiva, particularmente as que se relacionam com a estrutura económica da sociedade e com os diferenciais de classe economicamente definidos. A segunda traz à tona preocupações recentemente salientadas pela filosofia do reconhecimento, especialmente no que se refere à ordem de estatuto na sociedade e às hierarquias de estatuto culturalmente definidas. No entanto, nenhumas destas condições é apenas um epifenómeno da outra, sendo cada uma, pelo contrário, relativamente independente. Deste modo, nenhuma pode ser completamente efectivada de forma indirecta, através de reformas dirigidas exclusivamente para a outra. O resultado é uma concepção bidimensional de justiça que abrange tanto a distribuição como o reconhecimento, sem reduzir um aspecto ao outro.

Esta abordagem permite contrariar o risco de substituição no contexto da globalização. Ao analisar a redistribuição e o reconhecimento como duas dimensões mutuamente irredutíveis da justiça, amplia-se a sua con- 
cepção usual de modo a abarcar injustiças quer de estatuto, quer de classe. Ao submeter ambas as dimensões à norma englobante da paridade participativa, esta abordagem oferece um só critério normativo para avaliar tanto a estrutura económica como a ordem de estatuto. Assim, constitui o tipo de concepção lata de justiça de que precisamos a partir do momento em que resolvemos tratar a globalização nem como fatalidade nem como utopia, mas como um processo que envolve tanto recursos como riscos.

\section{Contrariar a reificação: uma concepção não-identitária de reconhecimento}

Uma segunda ameaça à justiça social no contexto da globalização surge como resultado de uma outra ironia histórica: as lutas pelo reconhecimento estão hoje a proliferar apesar (ou por causa) do aumento da interacção e comunicação transculturais. Isto é, manifestam-se precisamente quando a aceleração das migrações e dos fluxos dos meios de comunicação globais estão a fracturar e a hibridar todas as formas culturais, mesmo aquelas anteriormente vividas como "intactas". Em consonância, algumas lutas pelo reconhecimento procuram adaptar as instituições a esta condição de complexidade crescente. No entanto, muitas outras tomam a forma de um comunitarismo que simplifica e reifica drasticamente as identidades de grupo. Nestes casos, as lutas pelo reconhecimento não fomentam a interacção e o respeito entre diferenças em contextos cada vez mais multiculturais, mas tendem antes a encorajar o separatismo e a formação de enclaves grupais, o chauvinismo e a intolerância, o patriarcalismo e o autoritarismo. Chamo a isto o problema da reificação.

À semelhança da substituição, a reificação ameaça a nossa capacidade de conceptualizar a justiça social num contexto de globalização. Para neutralizar esta ameaça, precisamos de revisitar o conceito de reconhecimento. Necessitamos de uma concepção não-identitária que desencoraje a reificação e promova a interacção entre as diferenças, o que significa rejeitar as definições habituais de reconhecimento.

Geralmente, o reconhecimento é visto através da lente da identidade. Deste ponto de vista, o que requer reconhecimento é a identidade cultural específica dos grupos. O falso reconhecimento consiste na depreciação de tal identidade pelo grupo dominante e no consequente dano infligido ao sentido do eu dos membros do grupo. A reparação deste dano requer o envolvimento numa política de reconhecimento que visa rectificar a desestruturação interna através da contestação da imagem pejorativa do grupo projectada pela cultura dominante. Os membros desses grupos devem 
rejeitar tais imagens em favor de novas auto-representações por eles próprios construídas. Depois de remodelar a sua identidade colectiva, devem exibi-la publicamente de forma a ganhar o respeito e a consideração da sociedade em geral. Quando o resultado tem êxito, atinge-se o "reconhecimento", uma relação não distorcida consigo próprio. Relativamente ao modelo identitário, portanto, a política de reconhecimento significa política de identidade

É indubitável que este modelo identitário contém algumas ideias verdadeiramente esclarecedoras a respeito dos efeitos psicológicos do racismo, sexismo, colonização e imperialismo cultural. Contudo, falha em pelo menos dois aspectos importantes. Primeiro, tende a reificar as identidades de grupo e a ocultar eixos entrecruzados de subordinação. Em consequência, recicla frequentemente estereótipos relativos a grupos, ao mesmo tempo que fomenta o separatismo e o comunitarismo repressivo. Segundo, o modelo identitário trata o falso reconhecimento como um mal cultural independente e, como consequência, oculta as suas ligações com a má distribuição, impedindo assim os esforços para combater simultaneamente ambos os aspectos da injustiça.

Por estas razões, proponho uma concepção alternativa de reconhecimento. Na minha opinião, baseada no que pode designar-se por um "modelo de estatuto", o reconhecimento é uma questão de estatuto social. O que requer reconhecimento no contexto da globalização não é a identidade específica de um grupo, mas o estatuto individual dos seus membros como parceiros de pleno direito na interacção social. Desta forma, o falso reconhecimento não significa a depreciação e deformação da identidade do grupo, mas antes a subordinação social, isto é, o impedimento da participação paritária na vida social. A reparação desta injustiça requer uma política de reconhecimento, mas isto não significa uma política de identidade. No modelo de estatuto, pelo contrário, significa uma política que visa superar a subordinação através da instituição da parte reconhecida distorcidamente como membro pleno da sociedade, capaz de participar ao mesmo nível dos outros.

Passo a explicar. A aplicação do modelo de estatuto requer que examinemos os efeitos dos padrões institucionalizados de valor cultural sobre a posição relativa dos actores sociais. Nos casos em que tais padrões constituem os actores como pares, capazes de participar ao mesmo nível que os outros na vida social, então podemos falar de reconbecimento recíproco e de igualdade de estatuto. Quando, pelo contrário, os padrões institucionalizados de valor cultural constituem alguns actores como inferiores, excluídos, completamente outros ou simplesmente invisíveis, portanto como menos 
do que membros plenos na interacção social, então teremos de falar de falso reconbecimento ou subordinação de estatuto. Portanto, de acordo com o modelo de estatuto, o falso reconhecimento é uma relação social de subordinação transmitida através de padrões institucionalizados de valor cultural. Ocorre quando as instituições sociais regulam a interacção de acordo com normas culturais que impedem a paridade de participação. Os exemplos incluem leis matrimoniais que excluem uniões entre pessoas do mesmo sexo como ilegítimas e perversas, políticas sociais que estigmatizam as mães solteiras como parasitas sexualmente irresponsáveis e práticas de policiamento como a identificação por "perfil racial" que associam determinadas pessoas com a criminalidade. Em cada um destes casos, a interacção é regulada por um padrão institucionalizado de valor cultural que constitui algumas categorias de actores sociais como normativas e outras como deficientes ou inferiores. Consequentemente, é negado a alguns membros da sociedade o estatuto de parceiros plenos, capazes de participar na interacção ao mesmo nível que os outros.

Portanto, segundo o modelo de estatuto, o falso reconhecimento constitui uma grave violação da justiça. Sempre que ocorra e qualquer que seja a forma que tome, é necessário reivindicar o reconhecimento. Mas devemos notar o que isto significa em termos precisos: tal reivindicação não visa a valorização da identidade do grupo, mas a superação da subordinação, procurando instituir a parte subordinada como membro pleno na vida social, capaz de interagir paritariamente com os outros. Isto é, visa desinstitucionalizar padrões de valor cultural que impedem a paridade de participação $e$ substitui-los por padrões que a fomentam.

Conceber o reconhecimento a partir de um modelo de estatuto constitui um meio de contrariar a reificação no contexto da globalização. Ao concentrar-se, não na identidade de grupo, mas nos efeitos das normas institucionalizadas sobre as capacidades de interacção, evita o hipostasiar da cultura e a substituição da mudança social pela engenharia da identidade. Da mesma forma, ao recusar privilegiar remédios para o falso reconhecimento que valorizam as identidades de grupo existentes, evita a essencialização das actuais configurações e a recusa da mudança histórica. Por último, ao estabelecer a paridade participativa como critério normativo, o modelo de estatuto submete as reivindicações de reconhecimento a processos democráticos de justificação pública. Assim, evita o monologismo autoritário da política de autenticidade e valoriza a interacção transcultural por oposição ao separatismo e enclausuramento do grupo. Por conseguinte, longe de encorajar o comunitarismo repressivo, o modelo de estatuto combate-o frontalmente. 
Em termos gerais, portanto, esta abordagem fomenta o tipo de política de reconhecimento de que precisamos se tratarmos a globalização nem como fatalidade nem como utopia, mas como um contexto para as lutas de justiça social.

\section{Contrariar o enquadramento desajustado: uma concepção múltipla de soberania}

Há ainda uma terceira ameaça à justiça social na globalização. À semelhança da substituição e da reificação, esta é também resultado de uma ironia histórica: a globalização está a descentrar o enquadramento nacional de uma forma que torna cada vez menos plausível postular o Estado nacional como o único contexto de actuação e a única instância que contém em si e regula a justiça social. Nestas condições, torna-se imperativo colocar as questões no plano devido: tem de se determinar quais os assuntos que são verdadeiramente nacionais, quais são locais, regionais ou globais. Contudo, os conflitos actuais assumem um enquadramento desadequado. Por exemplo, há numerosos movimentos que procuram garantir enclaves étnicos precisamente numa altura em que a mistura crescente de populações está a tornar tais projectos utópicos. E há alguns defensores da redistribuição que se tornam proteccionistas precisamente numa altura em que a globalização económica está a fazer com que o keynesianismo seja impossível num país só. Nestes casos, o efeito não conduz à paridade de participação, mas antes à exacerbação das disparidades, ao impor à força um enquadramento nacional a processos que são inerentemente transnacionais. Chamo a isto $o$ problema do enquadramento desajustado.

Como a substituição e a reificação, o enquadramento desajustado ameaça a nossa capacidade de conceptualizar a justiça social num contexto de globalização. Para neutralizar esta ameaça, necessitamos de revisitar o problema do enquadramento. O que precisamos é de uma concepção múltipla que descentre o enquadramento nacional, pois só tal concepção permite acomodar toda a extensão de processos sociais que criam disparidades de participação na globalização.

A necessidade de tal concepção deriva dos desencontros de escala. Por exemplo, muitos dos processos económicos que regem a distribuição são claramente transnacionais. No entanto, os mecanismos redistributivos que herdámos do período fordista situam-se à escala nacional. Em consequência, há actualmente um óbvio desajustamento entre tais processos e mecanismos. É certo que instituições transnacionais como a União Europeia prometem ajudar a eliminar o fosso, mas elas próprias manifestam graves défices de justiça, tanto internamente (nas suas propensões neoliberais) como 
externamente (na sua tendência para erigir uma Fortaleza Europa). Para além de campanhas dispersas por medidas como o Imposto Tobin ou o Rendimento Básico Universal, até tempos recentes pouco tem surgido no horizonte que augure a superação deste desajustamento de escalas. Contudo, há pouco tempo, alguns segmentos do movimento emergente contra a globalização hegemónica neoliberal começaram a pensar seriamente sobre esta questão. Havendo mais avanços nesta direcção, o Fórum Social Mundial poderá ajudar a gerar ideias programáticas, bem como energias políticas.

De modo semelhante, muitos dos processos culturais que geram distinções de estatuto não podem confinar-se ao enquadramento nacional, na medida em que envolvem fluxos globais de signos e imagens, por um lado, e práticas locais de hibridação e apropriação, por outro. No entanto, os mecanismos usados para responder à subordinação de estatuto encontram-se instalados em larga medida dentro dos países ou Estados-nação, como era costume chamá-los. Portanto, também aqui encontramos um desajustamento. É certo que os novos mecanismos transnacionais para institucionalizar os direitos humanos, tais como o Tribunal Penal Internacional, oferecem algumas esperanças no que diz respeito ao preenchimento deste vazio, mas são ainda rudimentares e estão sujeitos às pressões dos Estados mais poderosos. De qualquer das formas, tais organizações são provavelmente demasiadamente globais, demasiadamente orientadas para universais abstractos para lidarem com todas as formas de subordinação de estatuto. Precisaremos de outras abordagens para lidar com as formas resultantes dos fluxos culturais que têm uma escala mais "glocal".

Em geral, nenhum dos enquadramentos por si só se ajusta a todas as questões de justiça no contexto da globalização. Como vimos, a justiça significa aqui a remoção dos obstáculos à paridade de participação. Porém, como vimos também, há pelo menos dois tipos de obstáculos - a má distribuição e o falso reconhecimento - que não se sobrepõem exactamente um ao outro. Sendo assim, não há garantias de que um enquadramento adequado a uma dimensão de justiça sirva também a outra. Pelo contrário, há muitos casos em que as reformas formuladas a partir de uma destas dimensões acabam por exacerbar a injustiça na outra.

De facto, a necessidade de enquadramentos múltiplos é parte inerente da ideia de paridade participativa. No fim e ao cabo, esse princípio não pode ser aplicado se não especificarmos qual a arena de participação social que está em causa e o conjunto de participantes que têm o direito de paridade dentro dela. Mas a norma da paridade participativa deve ser aplicada a toda a vida social. Assim, a justiça requer paridade de participação numa multiplicidade de contextos de interacção, que incluem os mercados de 
trabalho, as relações sexuais, a vida familiar, a esfera pública e as associações voluntárias da sociedade civil. Contudo, a participação tem significados diferentes em cada um desses contextos. Por exemplo, no mercado de trabalho o seu sentido é qualitativamente diferente da participação nas relações sexuais ou na sociedade civil. Portanto, o significado de paridade deve ser ajustado ao tipo de participação em questão. Da mesma forma, o conjunto de participantes com direito à paridade é delimitado diferentemente em cada um dos contextos. Por exemplo, o conjunto dos que têm direito à paridade nos mercados de trabalho pode ser maior do que o dos que têm o mesmo direito numa determinada associação voluntária da sociedade civil. Por conseguinte, o âmbito da aplicação do princípio deve ser ajustado ao contexto em questão, o que significa que não há uma fórmula única que baste para todos os casos. Daí que sejam necessários múltiplos enquadramentos.

Em termos gerais, então, não há nenhum enquadramento ou nível de soberania que por si só seja suficiente para lidar com a totalidade das questões de justiça no contexto da globalização. O que é preciso é antes um conjunto de enquadramentos múltiplos e uma concepção de soberania com múltiplos níveis. Consequentemente, torna-se inevitável a questão de saber quando e onde aplicar determinado enquadramento. A partir daqui, qualquer discussão sobre a justiça deve incorporar uma reflexão explícita sobre o problema do enquadramento. Relativamente a cada caso, devemos perguntar quem são precisamente os sujeitos relevantes da justiça e quem são os actores sociais entre os quais se exige que exista paridade de participação.

Anteriormente, antes da actual aceleração da globalização, a resposta a tais perguntas era em grande medida um dado adquirido. Partia-se do princípio, geralmente sem uma discussão explícita, de que as esferas da justiça coincidiam com os Estados e, portanto, que os indivíduos com direito a serem considerados eram concidadãos. Todavia, hoje em dia tal resposta já não é inquestionável. Dada a crescente relevância tanto dos processos transnacionais como dos subnacionais, o país já não pode funcionar como a única instância de justiça. Pelo contrário, apesar de continuar a ter importância, o país constitui apenas um de vários enquadramentos numa nova estrutura emergente de múltiplos níveis. Nesta situação, as deliberações acerca da institucionalização da justiça devem ter o cuidado de colocar as questões no plano adequado, determinando quais os assuntos que são verdadeiramente nacionais, locais, regionais ou globais. Elas têm de delimitar vários contextos de participação de forma a distinguir os conjuntos de participantes com direito a paridade dentro de cada uma delas. 
Portanto, em geral, a discussão explícita do enquadramento deve ter um papel central nas deliberações relativas à justiça, pois só assim poderá neutralizar-se o risco do seu desajustamento na globalização, entendida não como fatalidade ou utopia, mas como um contexto para lutar pela justiça.

\section{Conclusão}

Os três problemas que identifiquei - a reificação, a substituição e o enquadramento desajustado - são extremamente graves. Todos eles ameaçam a justiça social no contexto da globalização. Na medida em que a ênfase no reconhecimento está a levar à substituição da redistribuição, aquele pode vir efectivamente a fomentar a desigualdade económica. $\mathrm{Na}$ medida em que a viragem cultural está a reificar as identidades colectivas, corre-se o risco de se sancionar violações de direitos humanos e de se congelar os próprios antagonismos que esta viragem pretende mediar. Finalmente, na medida em que diferentes tipos de lutas estão a enquadrar desajustadamente os processos transnacionais, corre-se o risco de truncar o alcance da justiça e excluir actores sociais relevantes.

Propus neste texto três estratégias conceptuais para neutralizar estes riscos. Primeiro, para contrariar o risco da substituição, propus uma concepção bidimensional de justiça que abrange tanto o reconhecimento como a distribuição. Segundo, para contrariar a ameaça da reificação, propus uma concepção do reconhecimento baseada no estatuto que não conduz a uma política de identidade. Terceiro, para contrariar a ameaça do enquadramento desajustado, propus uma concepção de soberania de múltiplos níveis que descentra o enquadramento nacional. Todas estas propostas se baseiam em traços emergentes da globalização.

No seu conjunto, as três propostas constituem pelo menos uma parte dos recursos conceptuais de que precisamos para começar a responder àquilo que eu considero ser a mais importante questão política dos nossos dias: como poderemos delinear uma estratégia coerente para reparar as injustiças de estatuto e de classe no contexto da globalização? Como é que podemos integrar os melhores aspectos da política de redistribuição e da política de reconhecimento de forma a desafiar a injustiça em ambas as frentes? Se não conseguirmos responder a estas perguntas, se nos agarrarmos em vez disso a falsas antíteses e a enganadoras dicotomias, perderemos a oportunidade de conceptualizar formas de organização social que sejam capazes de reparar ao mesmo tempo a má distribuição e o falso reconhecimento. Só através da convergência dos dois objectivos num único esforço será possível cumprir os requisitos de justiça para todos. 